\title{
VIKTOR FRANKL: introdução aos estudos teóricos
}

\section{VIKTOR FRANKL: introduction to theoretical studies}

\author{
PEREIRA, Raquel Rinco Dutra. \\ Mestre em Educação pela Universidade Federal de Juiz de Fora. \\ Professora na Educação Básica. \\ E-mail: raquelrincodutra@gmail.com \\ ORCID ID: https://orcid.org/0000-0002-7727-1752 \\ MONTEIRO, Sandrelena da Silva. \\ Doutora em Educação pela Universidade Federal de Juiz de Fora. \\ Professora na Faculdade de Educação da Universidade Federal de Juiz de Fora. \\ E-mail: sandrelena.monteiro@ufjf.edu.br \\ ORCID ID: http://orcid.org/0000-0002-4920-6160
}

\section{RESUMO}

Enquanto professoras-pesquisadoras de uma universidade pública, sabemos que Viktor Frankl não é um autor tão presente nos currículos dos cursos de graduação, como o tem lugar Freud e Adler. Tal saber nos impulsiona a apresentar esse autor em uma linguagem que seja acessível aos estudantes, sem perder o rigor científico. Estabeleceu-se como objetivo apresentar esse autor a quem está começando a estudá-lo de forma que possam conhecer o caminho por ele construído e princípios defendidos a partir da compreensão de alguns conceitos basilares em sua teoria. Como metodologia elegeu-se a pesquisa bibliográfica com ênfase biográfica, uma vez que a vida e obra de Viktor Emil Frankl será nosso principal objeto de estudo no diálogo com ele mesmo e outros autores que possam contribuir nessa construção. É possível apontar que concepção de vida veiculada na Logoterapia e Análise Existencial se constitui referencial ao se pensar a construção de estratégias de resiliência na vida acadêmica, ressaltando especialmente a "força de resistência do espírito" e a "arte de viver a vida".

Palavras chave: Viktor Frankl; resiliência; vida acadêmica.

\section{ABSTRACT}

As researchers and teachers of a public university, we know that Viktor Frankl is not an author who has not the same recognize in graduation courses, as Freud and Adler have. This knowing drive we to present this author in a language that is accessible to students, without lose the scientific rigor. It was stablished as an objective to present this author to who is starting to study him in a way that they 
can cognize the path build by him and the defended principle light by the comprehension of some basic concepts in his theory. As methodology we elected the bibliographic research with biological emphasis, because the life and work of Viktor Frankl will be our main objective of study in dialog with himself and other authors the can contribute to this construction. It is possible to point that life's conception conveyed in Logotherapy and existential analyses constitutes referential when thinking about construction of resilience strategies in academic life, highlighting especially the "strong of resistance of spirit" and the "art of live the life".

Keywords: Viktor Frankl; resilience; academic life

\section{INTRODUÇÃO}

É notório, nos últimos anos, um número crescente de estudos buscando diálogo com a Teoria da Logoterapia e Análise Existencial de Viktor Frankl, uma pesquisa rápida pela página da internet confirma tal afirmativa. No entanto, não raras vezes, ainda que de forma inadvertida, lançamos mãos dos conceitos teóricos sem conhecer suas origens. Tal desconhecimento acaba por implicar em uma leitura superficial e com compreensões equivocada por não saber como tais conceitos foram construídos, em que contexto, no bojo de quais experiências. É com o objetivo de contribuir para a superação de tal fragilidade que esse artigo se propõe a, inicialmente, apresentar Viktor Emil Frankl a quem está começando a estudá-lo de forma que possam conhecer o caminho por ele construído e princípios defendidos a partir da compreensão de alguns conceitos basilares em sua teoria. Por fim, apontar como a concepção de vida veiculada na Logoterapia e Análise Existencial se constitui referencial ao se pensar a construção de estratégias de resiliência na vida acadêmica, ressaltando especialmente a "força de resistência do espírito" e a "arte de viver a vida".

Enquanto professoras-pesquisadoras de uma universidade pública, sabemos que Frankl não é um autor tão presente nos currículos dos cursos de graduação, como o tem lugar Freud e Adler. Tal saber nos impulsiona a apresentar esse autor em uma linguagem que seja acessível aos estudantes, sem perder o rigor científico, desejando que ao estudá-lo também possam encontrar sentido em seus cursos, em suas formações, em sua profissão, em sua vida.

Como metodologia elegemos a pesquisa bibliográfica com ênfase biográfica, uma vez que a vida e obra de Viktor Emil Frankl será nosso principal objeto de estudo no diálogo com ele mesmo e outros autores que possam contribuir nessa construção. 
Conhecer o nascimento de uma teoria e o contexto em que seus conceitos foram construídos é de fundamental importância para que possamos delas nos apropriar enquanto aporte teórico e quiçá metodológico em nossos saberes-fazeres acadêmicos e na vida.

\section{VIKTOR FRANKL: uma vida a ser conhecida e estudada}

Era dia 26 de março de 1905 quando nasceu Viktor Emil Frankl, em Viena, capital da Áustria, em uma família austríaca judia. O terceiro filho de Elsa e Gabriel: a mãe era descendente de uma família aristocrata de Praga, sobrinha-neta do poeta Oskar Wiener, e o pai, originário de Morávia, na época parte do Império Austro-Húngaro. Seu nascimento se deu no mesmo dia e mês da morte de Beethoven, razão pela qual um amigo sempre brincava: "Um desastre raramente vem desacompanhado" (FRANKL, 2010, p. 18).

Frankl se considerava uma pessoa tanto racional, característica herdada do pai, quanto emotiva, característica herdada da mãe. Com quatro anos, aproximadamente, descobriu que um dia iria morrer, assustando-se com essa realidade. Desde então, começou a se questionar pelo sentido da vida e por outras questões filosóficas.

Aos quinze anos, já se interessava pela Psicanálise, por isso se correspondia com Sigmund Freud (1856-1939), enviando-Ihe suas leituras e reflexões. Frankl lutava contra um sentimento particular de que tudo era um completo sem sentido. Porém, percebeu que Freud não se interessava pela busca do sentido na vida o que fez com que buscasse, em 1924, seguir Alfred Adler (1870-1937) e outros autores que se interessavam por esse assunto.

Em 1924, ingressou no curso de Medicina da Universidade de Viena, se especializando em Neurologia e Psiquiatria. Publicou artigos na Revista Internacional de Psicologia do Indivíduo e fundou a revista Der Mensch im Al/tag, tendo o apoio de dois seguidores de Adler, Oswald Schwarz e Rudolf Allers.

No ano de 1926, sob a influência de Max Scheler, dedicou-se a pesquisar como abordar, sob tratamento terapêutico, os problemas de ordem existencial e filosófica que seus pacientes apresentavam, o que lhe rendeu desentendimentos com Adler e sua expulsão da Sociedade Adleriana. Ainda, nesse ano, realizou uma conferência sobre Logoterapia, sendo essa a primeira vez que se pronunciou sobre esse tema para a academia.

Em 1927, inaugurou o primeiro centro de ajuda psíquica para jovens, num período em que as taxas de suicídios e problemas existenciais 
cresciam muito. Em 1930, concluiu sua formação em Neurologia e deu início a sua atuação em um hospital psiquiátrico em Viena. Entre os anos de 1933 a 1937, dedicou-se a proferir palestras sobre a Logoterapia, falando sobre o tema de forma mais aprofundada e concluiu sua especialização em Psiquiatra e Neurologia, além de assumir o cargo de diretor do Hospital Psiquiátrico Steinhof, em Viena.

Em 1938, Hitler anuncia a "união" entre a Alemanha a Áustria, que de fato era a anexação da Áustria à Alemanha nazista dando início às perseguições raciais.

Em 1939, Frankl consegue visto para emigrar para os Estados Unidos, porém fica indeciso de partir por ter que deixar seus pais. Angustiado, resolve visitar a Catedral no centro de Viena para que pudesse orar pedindo esclarecimento dessa dúvida: "Essa não é uma situação típica que pede por um sinal dos céus?" (FRANKL, 2010, p. 99).

Ao retornar à sua casa, encontra um pedaço de mármore que seu pai havia pegado nos restos de entulhos da maior sinagoga de Viena. Ao questioná-lo sobre do que se tratava, o pai lhe explicou que nessa peça se encontrava uma parte dos dez mandamentos, em que estava escrito: "Honrai teu pai e tua mãe, para que se prolongue seus dias na Terra". Frankl entendeu que essa era a resposta que precisava, permanecendo assim, com sua família.

Casou-se com Tilly Grosser em 1942, desfrutando poucos meses de seu matrimônio, pois, no mesmo ano, Frankl e sua família foram aprisionados. Identificado como prisioneiro de número 119.104, passou por quatro campos de concentração entre os anos de 1942 e 1945. Esse período foi caracterizado por ele como experimentum crucis, expressão latina que significa "experiência da cruz".

De acordo com Miguez (2014), os anos em que sofreu maus-tratos, as condições desumanas de sobrevivência, o sofrimento e a dor possibilitaram a experiência de "sua desnudez, descobrindo, como dizia, o homem em sua quintessência" (MIGUEZ, 2014, p. 20).

Sua experiência como prisioneiro permitiu desenvolver as convicções filosóficas e psicológicas que vinha formulando. Enfrentou os campos de concentração certo de que é possível o homem buscar o sentido da vida, mesmo que esteja passando por situações difíceis e até mesmo desumanas.

Frankl foi libertado do campo de concentração em 27 de abril de 1945. Voltou para Viena em agosto do mesmo ano e descobriu que toda a sua família havia falecido.

Ainda no ano de 1945 publicou seu livro mais famoso, "Em busca de 
sentido: um psicólogo no campo de concentração", ditado no espaço de tempo de nove dias. Esta obra, por seu teor impactante, foi publicada em mais de oitenta línguas. Sobre essa experiência, Frankl (2010) relata:

Eu não parava de ditar, três datilógrafas tinham de se revezar para dar conta de todas as passagens estenografadas e gravadas - tal a quantidade de ditados, brotando da alma, em salas sem aquecimento, pouco mobiliadas, "envidraçadas" com papelão. Eu andava pelos aposentos para cima e para baixo falando. De vez em quando, ainda consigo ver a cena, caí exausto numa cadeira e começava a chorar. Estava tão emocionado com minhas próprias lembranças, que muitas vezes me apareciam com dolorosa clareza. As comportas tinham sido abertas. (FRANKL, 2010, p. 124)

A princípio, Frankl escreveu esse livro com a intenção de lançá-lo anonimamente, com apenas seu número de prisioneiro, sem pretensão alguma de obter fama literária, pois não aprovava exibicionismo em relação às experiências de vida. Todavia, após grande insistência de seus amigos, concordou em publicá-lo com seu nome na página de rosto, "suplantando a aversão do exibicionismo com a coragem de confessar - superando-me assim a mim mesmo" (FRANKL, 2008, p. 8).

Sua intenção com esse livro era, além de ajudar as pessoas que se encontravam em situações de desespero, transmitir a mensagem "que a vida tem um sentido potencial sob quaisquer circunstâncias, mesmo as mais miseráveis" (FRANKL, 2008, p. 4).

Quando questionado por um repórter americano sobre como se sentia com tamanho sucesso do livro, respondeu-lhe:

Ao que costumo responder que, em primeiro lugar, vejo no status de bestseller do meu livro não tanto uma conquista e realização da minha parte, mas como uma expressão da miséria dos nossos tempos: se centenas de milhares de pessoas procuram um livro cujo título promete abordar o problema do sentido da vida, deve ser uma questão que as está queimando por dentro. (FRANKL, 2008, p. 4).

Ainda, em 1945, assumiu o posto de chefe do Departamento de Neurologia da Policlínica e depois de dois anos casou-se com Eleonore Schwindt, enfermeira da policlínica, com quem teve uma filha chamada Gabriela. 
No período do pós-guerra, dedicou-se a dar palestras nas principais academias da Europa e também à prática e ao ensino de psiquiatria em Viena. Foi homenageado com 29 títulos de doutor honoris causa em instituições de diversos países.

Frankl esteve no Brasil em 1984 para presidir o I Encontro LatinoAmericano Humanístico-Existencial: Logoterapia e para receber as chaves da cidade, além da Medalha Hóspede Oficial de Porto Alegre/RS e do título de doutor honoris causa pela PUC/RS (OLIVERIA, 2013). Retornou em 1985, para presidir o Encontro de Logoterapia em Brasília e, em 1986, para fazê-lo na cidade do Rio de Janeiro.

No ano de 1997, Frankl passou por uma cirurgia no coração e faleceu no Hospital de Viena com 92 anos. Deixou inúmeros ensinamentos e lições de vida, em especial a crença na capacidade humana de conseguir ver em cada situação algo de bom, ou seja, a capacidade humana de ser resiliente. Em suas próprias palavras:

O que importa é tirar o melhor de cada situação dada. 0 "melhor", no entanto, é o que em latim se chama optimum - daí o motivo por que falo de um otimismo trágico, isto é, um otimismo diante da tragédia e tendo em vista o potencial humano que, nos seus melhores aspectos, sempre permite: 1 . transformar o sofrimento numa conquista e numa realização humana; 2 . retirar da culpa a oportunidade de mudar a si mesmo para melhor; 3. fazer da transitoriedade da vida um incentivo para realizar ações responsáveis. (FRANKL, 2008, p. 75)

Algumas peculiaridades da personalidade de Frankl exerceram bastante influência em seu trabalho, dentre elas podemos destacar o alpinismo, considerado por ele uma grande paixão, praticando-o até os 80 anos. Nesses momentos da prática do esporte, tomava importantes decisões em sua vida: "Quase todas as minhas resoluções ou decisões importantes foram pensadas ou tomadas nesses caminhos solitários" (FRANKL, 2010, p. 46). Alguns amigos de Frankl acreditavam que a sua paixão pelo alpinismo vinha pelo interesse por uma "psicologia elevada" (FRANKL, 2010, p. 46), como ele próprio denominava a Logoterapia.

Outra peculiaridade é seu grande talento para caricaturas. Como caricaturista e psiquiatra, percebia os pontos fracos das pessoas e, assim, as auxiliava na superação de si mesmas. Frankl (2010, p. 57) afirmava que "descobrir intuitivamente as possibilidades (facultativas) para superar essas fraquezas, e para além da desgraça de uma situação, ainda posso rastrear as possibilidades de dar um sentido a essa situação e assim transformar o sofrimento aparentemente sem sentido num feito humano 
real".

Extremamente exigente consigo mesmo, se considerava um perfeccionista e, por isso, gostava de planejar suas atividades antecipadamente, não deixando nada para a última hora. Fazia assim alguns acordos consigo mesmo: não deixar nada para a última hora, dedicar-se às coisas pequenas com o mesmo cuidado que se dedicava às coisas grandes, fazer primeiro as coisas desagradáveis para depois fazer as agradáveis, economizar tempo e, enfim, superar-se, superar-se... Sobre esses acordos, algumas vezes cometia "infidelidades". Nesses momentos, dizia: "Claro que fico bravo comigo quando isso acontece - costumo dizer: tão bravo, que passo dias sem me dirigir a palavra" (FRANKL, 2010, p. 35).

Curiosamente cultivava alguns hobbies que considerava "sem importância": 1 - Amava café a ponto de levar comprimidos de cafeína nas suas viagens. Caso não conseguisse tomar um café forte antes de realizar uma palestra, ingeria um comprimido; 2 - Os pastéis também eram um capítulo à parte no quesito preferência gastronômica; 3- Gostava muito de cultivar a arte do diletantismo e chegou a compor um tango para sua primeira esposa Tilly; 4 - Era um grande apreciador de gravatas, podendo contemplá-las mesmo que platonicamente: "Posso admirá-las quando estão em exposição, ou seja, mesmo quando sei que não são minhas e nunca serão" (FRANKL, 2010, p. 47); 5 - Admirava armação de óculos, tornando-se tão entender do assunto que uma empresa lhe apresentou modelos para que pudesse avaliá-los.

Em suas características pessoais era um homem, como muitos outros homens e talvez em nada diferencia não fosse sua capacidade de ver a vida como um campo de possibilidade, cheio de sentidos as serem descobertos.

\section{LOGOTERAPIA E ANÁLISE EXISTENCIAL: uma construção}

O termo logos é uma palavra grega que significa "sentido". Portanto, Logoterapia, segundo Frankl (2008), concentra-se no sentido da existência humana, bem como na busca da pessoa por este sentido.

O termo Logoterapia foi usado publicamente pela primeira vez em 1926 e, a partir de 1933, passou a ser usada juntamente com a expressão complementar "Análise Existencial". Em pouco tempo passou a ser considerada a terceira escola vienense de psicoterapia, precedida pela Psicanálise de Freud e pela Psicologia Individual de Adler.

Frankl (2019) considera impossível falar de psicoterapia sem se referir a Freud e Adler, aos quais nutria grande admiração, considerando a obra de ambos como "os dois únicos grandes sistemas no âmbito 
psicoterápico" (FRANKL, 2019, p. 31).

Segundo Meireles (2019), uma das críticas que Frankl tece em relação à Psicanálise e à Psicologia Individual é o fato de estas desconsiderarem o ser humano em sua totalidade, ou seja, em suas dimensões corpóreo-psíquico-espiritual, dissolvendo, assim, "a dimensão existencial expressa pela tríade Eros, Logos e Ethos, incorrendo no erro psicologista" (MEIRELES, 2019, p. 23).

No tocante à psicanálise e à psicologia individual, Frankl (2019) ainda afirma que

[...] a psicanálise ensejou-nos o conhecimento da vontade de prazer, conforme podemos interpretar o princípio do prazer. A psicologia individual familiarizou-nos com a vontade de poder, na forma de aspiração ao êxito. Na realidade, porém 0 ser humano é profundamente permeado por uma vontade de sentido. (FRANKL, 2019, p. 37)

Dessa forma, para a Logoterapia e Análise Existencial, "a busca de sentido na vida da pessoa é a principal força motivadora no ser humano" (FRANKL, 2008, p. 58), portanto, ultrapassa os princípios da psicanálise e da psicologia individual sem, no entanto, desconsiderá-las. Todavia, é importante destacar que a Logoterapia é aberta à cooperação de outras concepções psicológicas, como também é aberta à sua própria evolução.

No tocante ao sentido na vida, Frankl (2019, p. 153) ressalta a existência de "elementos constitutivos do sentido da vida humana" como o caráter único e irrepetível do ser humano. Cada ser humano possui suas características únicas, portanto, se difere dos demais, assim como cada peça num mosaico se difere das outras. 0 autor a esse respeito afirma "com efeito, o essencial e valioso caráter de algo único de cada homem não significa senão que ele é precisamente diferente de todos os outros homens" (FRANKL, 2019, p. 154).

Por mais que uma pessoa se assemelhe a outra, cada ser humano é único. Cada existência, dessa forma, tem o caráter de algo único e irrepetível, possuindo o homem liberdade para agir em sua existência, mas também responsabilidade para responder por suas ações.

De acordo com Peter (1999, p. 19), "a coluna de sustentação antropológica da Logoterapia é: o homem não apenas decide sobre alguma coisa ou de alguma coisa, mas decide sobre si mesmo". Portanto, mesmo diante dos condicionamentos físicos, psíquicos e sociológicos, o homem tem a liberdade para decidir e se posicionar diante da vida. O próprio Frankl foi testemunha que é possível o ser humano ser livre para se opor às mais difíceis situações de opressão. 
Sendo assim, segundo Peter (1999), o ser humano é concebido por Frankl em sua totalidade, ou seja, nas dimensões física, psíquica e espiritual, sendo uma unidade apesar da pluralidade. Essas dimensões,

\begin{abstract}
[...] tornam-se ontologicamente diversas, porém antropologicamente inseparáveis, na medida em que a dimensão superior (noética) unifica e agrupa em torno do próprio núcleo a globalidade do ser-homem. Somente assim o homem resulta numa verdadeira unitas multiplex. (PETER, 1999, p. 38)
\end{abstract}

Na dimensão espiritual, também chamada de dimensão noética, a palavra nous vem do grego e significa "espírito". Nela, se manifestam os fenômenos específicos do ser humano como a responsabilidade, autotranscendência, autocompreensão, a liberdade de vontade, a vontade de sentido e o sentido da vida, fenômenos esses que estão intrinsecamente ligados à capacidade de resiliência.

A autotranscendência e a autocompreensão são características antropológicas do ser humano defendido por Frankl. A autotranscendência é a capacidade humana de se voltar para algo ou alguém diferente de si mesmo. Santos (2016, p. 132) afirma que "quanto mais a pessoa esquece de si mesma, dedicando-se a uma causa ou a alguém, mais humana se torna. Ela não se fecha em condicionamentos, mas os transcende". Braga (2020), ao estudar a configuração do estado de tédio durante o período da pandemia da COVID-19, aponta que a resposta à vida "quando dada a partir da "autotranscendencia", é capaz de conferir a sentido à realidade mais difícil, inclusive a realidade desconcertante do tédio" (p. 13).

Sobre a autotranscendência, Frankl (2019, p. 155) aponta os ensinamentos para vida citados por Hillel, "Se eu não faço, quem o fará? E se eu não faço agora, quando se fará? - E, se só para mim o faço, o que é que eu sou afinal?".

Segundo Frankl (2011), a capacidade de autotranscendência do ser humano se manifesta por meio do amor e da consciência. O amor na concepção frankliana não tem relação com "sentimentalismo barato, tampouco com mera satisfação sexual - antes, o sexo é um meio de expressão do amor" (SANTOS, 2016, p. 132). O amor, para Frankl (2008), está relacionado com a capacidade de ver além das aparências, considerando não só as características do ser humano, mas também as suas potencialidades, ou seja, a sua essência:

Amor é a única maneira de captar outro ser humano no íntimo da sua personalidade. Ninguém consegue ter consciência plena da essência última de outro ser humano 
sem amá-lo. Por seu amor a pessoa se torna capaz de ver os traços característicos e as feições essenciais do seu amado; mais ainda, ela vê o que está potencialmente contido nele, aquilo que ainda não está, mas deveria ser realizado. Além disso, através do seu amor a pessoa que ama capacita a pessoa amada a realizar estas potencialidades. Conscientizando-a do que ela pode ser e do que deveria vir a ser, aquele que ama faz com que estas potencialidades venham a se realizar. (FRANKL, 2008, p. 64)

Assim, no sentido verdadeiro do amor, ninguém pode substituir o ser amado "dado o seu caráter de algo único e irrepetível" (FRANKL, 2019, p. 227).

Já a consciência, considerada por Frankl (2019, p. 107) como "órgãosentido", é parte integrante dos fenômenos específicos do ser humano. 0 autor a define como "a capacidade intuitiva para seguir o rastro do sentido irrepetível e único que se esconde em cada situação" (FRANKL, 2019, p. 106). Segundo Peter (1999, p. 64), "a consciência efetivamente é toda intuição, porque tem a função de abrir e manifestar aquilo que deve ser".

No tocante ao conceito de autodistanciamento, para Frankl (2008), está relacionado à capacidade de distanciar-se de si mesmo, ou seja, distanciar dos desafios para que se possa enxergá-los de outra maneira. Embora o ser humano não esteja livre dos condicionamentos, está livre para se posicionar de forma positiva diante das situações pelas quais passa numa atitude de resiliência. Como o fez o próprio Frankl, quando viveu situações difíceis nos campos de concentração.

A capacidade de autodistanciamento pode ser manifestada também através do humor, ou seja, na capacidade de rir apesar das dificuldades. Quando o ser humano é capaz de rir das situações é capaz de distanciarse delas. Ou seja,

[...] esse distanciar-se da situação, especialmente, quando esta Ihe for difícil, faz com que a pessoa esteja espiritualmente mais afastada, permitindo então compreender que ela própria não é a situação, não é o que lhe acontece, não é a sua limitação. (SANTOS, 2016, p. 132)

É o próprio Frankl (2008) que nos ensina essa atitude, quando, ainda no campo de concentração, propôs a um amigo o compromisso mútuo de inventar pelo menos uma piada por dia com as situações difíceis pelas quais passavam, mostrando que, mesmo numa situação extrema, o ser humano tem a liberdade para encontrar saídas para o sofrimento. Segundo 
o autor, "a vontade de humor - a tentativa de enxergar as coisas numa perspectiva engraçada - constitui um truque útil para a arte de viver" (FRANKL, 2008, p. 29).

$O$ autodistanciamento também pode se manifestar através da autocompreensão que, segundo Santos (2016), constitui a capacidade de compreender a si mesmo, desvelando e compreendendo assim as características íntimas de cada ser, como seus desafios e também as suas potencialidades. Mediante as situações adversas, perante aos impulsos de agressividade através da autocompreensão, a pessoa é capaz de refletir sobre as suas ações tomando atitudes mais equilibradas e assertivas.

Dessa forma, o ser humano é livre para escolher o caminho e construir sua história de vida, possuindo assim liberdade de escolha. Para Frankl (2008), a liberdade é uma característica específica do ser humano, que embora não esteja livre dos condicionantes biopsicossociais, está livre para decidir sobre seu destino. Segundo Miguez (2014), o homem é livre para se posicionar perante a si mesmo e perante as situações que a vida Ihe apresenta, pois possui a capacidade de "distanciar-se da situação sem diluir-se nela, ou distanciar-se do psicofísico sem identificar-se com ele" (MIGUEZ, 2014, p. 39).

Dessa forma, Frankl (2008) afirma que

[...] mesmo uma vítima sem recursos, numa situação sem esperança, enfrentando um destino que não pode mudar, pode erguer-se acima de si mesma, crescer para além de si mesma e, assim, mudar-se a si mesma. Pode transformar a tragédia pessoal em triunfo. (FRANKL, 2008, p. 79)

Porém, de acordo com o autor, a liberdade deve vir sempre acompanhada da responsabilidade, sendo esses dois elementos constitutivos um do outro. Nas palavras de Santos (2016, p. 6), "a própria finitude e caráter único da vida de cada um convoca a responsabilidade do ser perante a sua existência".

A responsabilidade, segundo Frankl (2008), é a capacidade de assumir aquilo que decidimos e aquilo que fazemos. Daí a importância da liberdade caminhar lado a lado com a responsabilidade.

Santos (2016) afirma que é importante que cada ser humano responda às seguintes indagações: "Diante de quem ele se sente responsável (por exemplo, diante da sua própria consciência, da sociedade ou mesmo de Deus); e pelo que ele se sente responsável?" (SANTOS, 2016, p. 133).

A responsabilidade perante a alguém ou a algo leva o ser humano a buscar por um sentido na vida, o que Frankl (2011, p. 50) denomina como 
vontade de sentido, ou seja, "o esforço mais básico do homem na direção de encontrar e realizar sentidos e propósitos". A vontade de sentido, segundo Santos (2016), é a manifestação primordial da autotranscendência. Por outro lado, Frankl (2008, p. 61) afirma que "quando a vontade livre é frustrada gera uma sensação de vazio e falta de sentido, o que ele denomina como vazio existencial".

Para exemplificar, Frankl (2008) relata uma pesquisa realizada com seus alunos que revelou que $25 \%$ de seus alunos europeus apresentavam um grau relativamente acentuado de vazio existencial, porém a porcentagem de seus alunos norte-americanos era bem mais expressiva, $60 \%$.

Outra pesquisa relatada por Frankl (2019) diz respeito aos estudos realizados por Rolf von Eckartsberg, da Universidade de Harvard, que se estendeu por 20 anos. Foram pesquisados 100 antigos estudantes de Harvard que obtiveram êxito em suas escolhas profissionais, sendo que $25 \%$ destes relataram enfrentar "crise relativa ao problema do sentido da vida" (FRANKL, 2019, p. 46).

Frankl (2008) presume, portanto, que o vazio existencial seja um fenômeno característico do século XX, sendo atribuído a perda que o ser humano sofre dos instintos animais básicos que possuía e que garantiam a sua sobrevivência e das tradições que apoiavam o seu comportamento. Assim, não há mais instintos e nem tradições que mostrem o que fazer e como fazer.

Com a perda dessas referências, o ser humano faz o que desejam que ele faça. A isso, Frankl (2008, p. 62) denomina como "totalitarismo". Ou realiza algo como as outras pessoas realizam, a que Frankl (2008, p. 62) denomina como "conformismo". Tanto em uma situação, quanto na outra, o ser vai perdendo as suas próprias referências.

Segundo Frankl (2008), o vazio existencial se manifesta na nossa sociedade através de uma tríade de aspectos: depressão, dependência química e agressão. A depressão, como a dependência química, pode resultar no suicídio. $\mathrm{O}$ autor, entretanto, alerta que:

[...] nem todo caso de depressão pode ser atribuído a um sentimento de falta de sentido. Tampouco o suicídio - a que a depressão às vezes leva a pessoa - sempre é resultado de um vazio existencial. Contudo, mesmo que todo e qualquer caso de suicídio não tenha sido levado a cabo por causa de um sentimento de falta de sentido, é bem possível que o impulso de tirar a vida tivesse sido superado se a pessoa tivesse estado consciente de algum sentido e propósito pelos quais valesse a pena viver. (FRANKL, 2008, p. 77) 
O autor ainda afirma que mais importante do que questionar a uma pessoa o que a motiva a querer cometer suicídio, é se preocupar com o que a faz se afastar dessa vontade, pois "é bem possível que o impulso de tirar a vida tivesse sido superado se a pessoa tivesse estado consciente de algum sentido e propósito pelos quais valesse a pena viver" (FRANKL, 2019, p. 165), ou seja, o sentido na vida.

O sentido na vida, para Frankl (2008), é algo particular a cada pessoa e a cada momento, ou seja, "difere de pessoa para pessoa, de um dia para outro e de uma hora para outra" (FRANKL, 2008, p. 62). Assim, a tarefa de encontrar um sentido na vida é algo singular a cada ser humano. Isso porque

[...] cada situação na vida representa um desafio para a pessoa e lhe apresenta um problema para resolver, podese, a rigor, inventar a questão pelo sentido da vida. Em última análise, a pessoa não deveria perguntar qual o sentido da sua vida, mas antes deve reconhecer que é ela que está sendo indagada. (FRANKL, 2008, p. 63)

O sentido que cada um dá a sua vida é fundamentado por valores tais como de: criação; experiência (ou vivência); atitude que tomamos frente ao sofrimento inevitável.

Os valores da criação estão relacionados a algo que o ser humano oferece ao mundo, seja através de seus atos de transformação das pessoas a sua volta, o ambiente que o cerca, ou até mesmo no trabalho. Santos (2016, p. 138) ressalta que "não se trata do trabalho pelo trabalho ou apenas de executar tarefas, mas do sentido que a pessoa dá aos seus atos nesse contexto".

Os valores da experiência referem-se a algo que o homem recebe do mundo, por exemplo, a bondade, as experiências com a natureza, a cultura e o amor. De acordo com Santos (2016, p. 138), é "um valor bastante amplo, já que pode ser experimentado de diversas formas".

Para exemplificar uma dessas formas, tomo a experiência citada por Frankl (2019): uma pessoa, ao escutar os compassos mais marcantes de sua sinfonia preferida, sentindo uma emoção indescritível, pode acreditar que sua vida foi plena de sentido, mesmo por um breve instante; "com efeito, embora, se trate de um só momento, pela grandeza de um momento já se pode medir a grandeza de uma vida" (FRANKL, 2019, p. 113).

E, por fim, os valores que estão ligados à atitude do ser humano perante a vida e o sofrimento. É a atitude que tomamos frente a algo que não se pode mudar em nossas vidas, "na busca de vivenciar tal situação com dignidade, com coragem. Se a vida tem sentido, o sofrer, que é 
inerente ao ser humano, também tem" (SANTOS, 2016, p. 138).

Na leitura de Aquino e Cruz (2020b, p. 360)

De maneira geral, as pessoas encontram sentido ao realizar valores criativos, mas que trabalho criativo dará sentido à vida de um indivíduo seria singular. O ser humano encontra sentido ao vivenciar algo ou alguém, mas o que ele irá vivenciar ou quem irá amar é único. Por fim, a postura que o ser humano toma perante um destino trágico é uma via de realização humana, mas a postura que dará sentido ao sofrimento, no entanto, seria particular.

Todos esses valores podem culminar em atitudes otimistas e esperançosas perante os percalços da vida, ou seja, em atitudes de resiliência. É valido ressaltar que essas atitudes não são conformistas, ao contrário, são atitudes de mudanças de algo negativo em positivo, de derrota em superação. Isso porque as adversidades são inerentes à vida humana e possibilitam o crescimento e amadurecimento.

$\mathrm{Na}$ leitura de Aquino e Cruz (2020a) e Freitas (2017) o conceito de resiliência, enquanto força de enfrentamento das situações de sofrimento pode ser entendido como o que Frankl nomeou o "poder de resistência do espírito". Aqui é possível entender que, embora o ser humano não esteja livre dos condicionamentos psicológicos, biológicos e sociológicos, ainda assim é livre para se posicionar ante os acontecimentos da vida.

[...] sou sobrevivente de quatro campos de concentração e por isso também sei perfeitamente até onde vai a liberdade do homem, que é capaz de se elevar acima de toda a sua condicionalidade e resistir às mais rigorosas e duras condições e circunstâncias, escorando-se naquela força que costumo denominar o poder de resistência do espírito. (FRANKL, 2019, p. 63)

Portanto, mediante essas considerações, pode-se concluir que o poder de resistência do espírito permite ao sujeito a capacidade de ser resiliente, ou seja, tornar-se um sujeito crítico de sua situação existencial e livre para decidir e construir o seu próprio caminhar e dizer sim, apesar de tudo, "graças a uma pitada de ars vivendi"(FRANKL, 2010, p. 36). Em outras palavras, a arte de viver a vida. 


\section{CONSIDERAÇÕES FINAIS}

Conhecer os conceitos básicos de uma teoria e o contexto de vida em que foram construídos é exercício fundamental para quem pretende trabalhar com a mesma. Particularmente no recorte feito nessa escrita, entende-se que os construtos teoria de Viktor Frankl podem se constitui referencial ao se pensar a construção de estratégias de resiliência na vida acadêmica, ressaltando especialmente a "força de resistência do espírito" e a "arte de viver a vida". Como bem ressalta Freitas (2017, p. 144) a "atitude resiliente é um grande fator protetor da saúde física e mental". Enfrentar os desafios inerentes à vida acadêmica de forma resiliente ajuda os jovens estudantes a encontrar os sentidos aí existentes, e a fazer valer os motivos e que os levaram até ali.

Viktor Emil Frankl é um autor que tem contribuído em nossas pesquisa e ações de extensão universitária tanto como referencial teórico, quanto como aporte metodológico. $\mathrm{E}$, ainda, como exemplo de vida, uma vez que, ao expor sua experiência de vida e usá-la para exemplificar os conceitos teóricos construídos aproxima teoria e prática. Com essa aproximação aponta a presença dos conceitos em nossas vidas cotidianas e então, a possibilidade de também os experimentá-los, especialmente ante as situações de adversidades.

Por fim, o estudo da teoria da Logoterapia e Análise Existencial de Viktor Frankl é um convite a ser mais, a ser exatamente o que podemos vir a ser, não obstante os desafios que a vida nos impõe.

\section{REFERÊNCIAS}

AQUINO, Thiago A. Avellar; CRUZ, Josilene Silva da. Espiritualidade e resiliência: relevância e implicações no pensamento frankliano. REVER Revista de Estudos da Religião, v. 20, n. 2, 2020a. Disponível em: https://revistas.pucsp.br/index.php/rever/article/view/50686/33093. Acesso em: 08 dez. 2020.

AQUINO, Thiago A. Avellar; CRUZ, Josilene Silva da. A questão da transcendência dos valores e do sentido da vida na análise existencial de Viktor Frankl. In: REVER - Revista de Estudos da Religião, v. 34, n, 2, p. 351-367. Maio-ago. 2020b. Disponível em: https://www.metodista.br /revistas/revistas-metodista/index.php/ER/article/view/10532 Acesso em 12 jul. 2021.

BRAGA, Arnim Rommel Pinheiro. Tédio e sentido na Pandemia: uma análise a partir do pensamento de Viktor Frankl. In: Complexitas. Ver.Fil. Tem. 
Belém, v. 5, n. 1, p. 67-79, jan/dec. 2020. Disponível em: https://periodicos.ufpa.br/index.php/complexitas/article/view/9323 Acesso em 12 jul. 2021.

FRANKL, Viktor Emil. Em busca de sentido: um psicólogo no campo de concentração. Petrópolis: Vozes, 2008.

FRANKL, Viktor Emil. Memórias: o que não está escrito nos meus livros. São Paulo: É Realizações Editora, 2010

FRANKL, Viktor Emil. A vontade de sentido: fundamentos e aplicações da Logoterapia. São Paulo: Paulus, 2011.

FRANKL, Viktor Emil. O sofrimento de uma vida sem sentido: caminhos para encontrar a razão de viver. São Paulo: É Realizações, 2015.

FRANKL, Viktor Emil. Psicoterapia e sentido da vida: fundamentos da Logoterapia e Análise Existencial. São Paulo: Quadrante, 2019.

FREITAS, Marina Lemos Silveira. Pedagogia do Sentido: contribuições de Viktor Frankl para a educação. Ribeirão Preto: IECVF, 2017.

MEIRELES, Marcus Vinícius da Costa. Filosofia e Psicoterapia no projeto da Análise Existencial de Viktor Frankl: a compreensão da pessoa espiritual a partir da transcendência. Doutorado em Ciência da Religião. Universidade Federal de Juiz de Fora, Juiz de Fora. 2019. Disponível em https://repositorio.ufjf.br/jspui/bitstream/ufjf/11209/1/ marcosviniciusdacostameireles.pdf Acesso em: 12 jul. 2021.

MIGUEZ, Eloisa Marques. Educação em busca de sentido: Pedagogia inspirada em Viktor Frankl. São Paulo: Paulus, 2014.

PETER, Ricardo. Viktor Frankl: a antropologia como terapia. São Paulo: Paulus, 1999.

SANTOS, David Moisés Barreto dos. Logoterapia: compreendendo a teoria através de mapas de conceitos. Arquivos Brasileiros de Psicologia, Rio de Janeiro, 68(2). 2016. Disponível em: http://pepsic.bvsalud.org/pdf/ arbp/v68n2/v68n2a11.pdf Acesso em 12 jul. 2021.

Recebido em: 14/07/2021

Aceite em: 04/12/2021 